\title{
Interventions to increase referral and uptake to pulmonary rehabilitation in people with COPD: a systematic review
}

This article was published in the following Dove Press journal: International Journal of COPD

\section{Frances Early' \\ lan Wellwood ${ }^{2}$ \\ Isla Kuhn ${ }^{3}$ \\ Christi Deaton ${ }^{2}$ \\ Jonathan Fuld'}

'Centre for Self-Management Support, Cambridge University Hospitals NHS Foundation Trust, Cambridge, UK; ${ }^{2}$ Clinical Nursing Research Group, Primary Care Unit, Department of Public Health and Primary Care, University of Cambridge School of Clinical Medicine, Cambridge, UK; ${ }^{3}$ Medical Library, University of Cambridge School of Clinical Medicine, Cambridge, UK
Correspondence: Frances Early Centre for Self-Management Support, Box 146, Cambridge University Hospitals NHS Foundation Trust, Cambridge Biomedical Campus, Hills Road,

Cambridge CB2 0QQ, UK

Tel +44 I22 3274858

Email frances.early@addenbrookes. nhs.uk

\begin{abstract}
Pulmonary rehabilitation (PR) reduces the number and duration of hospital admissions and readmissions, and improves health-related quality of life in patients with COPD. Despite clinical guideline recommendations, under-referral and limited uptake to PR contribute to poor treatment access. We reviewed published literature on the effectiveness of interventions to improve referral to and uptake of PR in patients with COPD when compared to standard care, alternative interventions, or no intervention. The review followed recognized methods. Search terms included "pulmonary rehabilitation" AND "referral" OR "uptake" applied to MEDLINE, EMBASE, CINAHL, PsycINFO, ASSIA, BNI, Web of Science, and Cochrane Library up to January 2018. Titles, abstracts, and full papers were reviewed independently and quality appraised. The protocol was registered (PROSPERO \# 2016:CRD42016043762). We screened 5,328 references. Fourteen papers met the inclusion criteria. Ten assessed referral and five assessed uptake (46,146 patients, 409 clinicians, 82 hospital departments, 122 general practices). One was a systematic review which assessed uptake. Designs, interventions, and scope of studies were diverse, often part of multifaceted evidence-based management of COPD. Examples included computer-based prompts at practice nurse review, patient information, clinician education, and financial incentives. Four studies reported statistically significant improvements in referral (range 3.5\%-36\%). Two studies reported statistically significant increases in uptake (range 18\%-21.5\%). Most studies had methodological and reporting limitations. Meta-analysis was not conducted due to heterogeneity of study designs. This review demonstrates the range of approaches aimed at increasing referral and uptake to PR but identifies limited evidence of effectiveness due to the heterogeneity and limitations of study designs. Research using robust methods with clear descriptions of intervention, setting, and target population is required to optimize access to PR across a range of settings.
\end{abstract}

Keywords: health services research, service improvement, access to healthcare, evidence-based practice, long-term condition, supervised exercise

\section{Introduction}

COPD presents a considerable health challenge. It is estimated that worldwide 328 million people have COPD and 65 million people live with moderate to severe COPD. ${ }^{1}$ In 2015, COPD accounted for 5\% of all deaths globally, ${ }^{2}$ and in the UK, $\sim 1.2$ million people and $4.5 \%$ of all people aged over 40 years live with the condition. ${ }^{3}$ COPD is likely to be underdiagnosed and prevalence in the UK may be rising. ${ }^{3}$ It compromises individuals' quality of life and impacts healthcare costs, mostly relating to hospital admissions. In 2012, it was estimated to cost the UK National Health Service $£ 800$ million per annum. ${ }^{4}$ Pulmonary rehabilitation (PR), providing supervised 
exercise and education, improves COPD symptoms leading to improvements in exercise capacity and quality of life. ${ }^{5}$ PR reduces the number and duration of respiratory hospital admissions experienced by individuals, ${ }^{6}$ the number of readmissions, ${ }^{6,7}$ and can foster self-management skills. ${ }^{8}$ It is a cost-effective treatment. ${ }^{9}$

Despite a clear evidence base and guidelines recommending PR, ${ }^{10,11}$ it is grossly underutilized in practice worldwide. ${ }^{12}$ In England and Wales, for example, the National COPD Audit Programme for 2013/14 estimated the prevalence of COPD patients eligible for PR to be 446,000; however, only 68,000 were referred (15\% of normative need) of whom only $69 \%$ attended an initial assessment (10\% of normative need). ${ }^{13}$ Utilization may be impacted by availability, referral, and uptake but even where places are available they may not be utilized. In the East of England in 2014/15, the number of available PR places represented only $53.8 \%$ of the proposed target, but just $73 \%$ of these places were taken up. ${ }^{14}$ There is an urgent need to improve referral and uptake to PR both in the $\mathrm{UK}^{6,13}$ and globally ${ }^{12}$ but there is no best practice guidance for doing so.

We set out to conduct a systematic review of published studies on the effectiveness of interventions to increase rates of referral and uptake from primary care or outpatient departments to exercise-based PR programs in patients with COPD compared to standard care, alternative interventions, or no intervention.

\section{Methods}

Recognized systematic review methods ${ }^{15}$ were adapted to conduct the review. The review protocol was registered on PROSPERO (2016:CRD42016043762) ${ }^{16}$ and reported according to PRISMA guidelines. ${ }^{17}$

\section{Eligibility}

Studies were required to report at least one of the main outcomes of interest: rates of referral to or uptake of exercisebased PR programs in patients with COPD. We defined PR programs as including "multicomponent, multidisciplinary interventions, which are tailored to the individual patient's needs. The rehabilitation process should incorporate a program of physical training, disease education, and nutritional, psychological, and behavioral intervention." 18 Uptake was defined as having attended a first appointment with a PR provider including initial assessment.

We included all studies that used established quantitative or mixed methods of data collection, eg, trials, surveys, direct observations, action research, interviews, focus groups or questionnaires, systematic reviews, and meta-analyses. Interventions could be contrasted with standard care, alternative interventions, or have no comparator or control.

We included studies of i) healthcare professionals who referred COPD patients to PR in primary, secondary, or community care settings; ii) adult patients ( $\geq 18$ years) with a diagnosis of COPD in any setting, who had received a referral to PR (whether taken up or not); and iii) informal adult carers ( $\geq 18$ years) of these patients, defined as spouse or partner, family members, friends, or significant others, who provided physical, practical, transportation, or emotional help to someone with COPD. We excluded professional carers. We also excluded studies that featured mixed participant groups where subgroups with COPD were not described or where studies were conducted in various settings and data from inpatient and outpatient services could not be separated.

Published studies were included. Conference abstracts and opinion papers were not considered for analysis. No language restrictions were applied.

\section{Data sources and search strategy}

We searched the following databases: MEDLINE and EMBASE (via OVID), CINAHL and PsycINFO (via EbscoHost), ASSIA and BNI (via ProQuest), Web of Science, and Cochrane Library to the end of January 2018. A search strategy was developed on MEDLINE (see Supplementary material) and adapted for other databases. The strategy included "quantitative" OR "mix* method*." Filters for randomized controlled trials (RCTs) and systematic reviews were adapted from Scottish Intercollegiate Guidelines Network search filters. ${ }^{19}$ We also searched "related article" searches in PubMed for all studies included in the review and scanned reference lists of all included studies and key references, searching for relevant papers citing the included papers in the Institute for Scientific Information Web of Science (Science Citation Index and Social Sciences Citation Index). An interim report of this work, searching literature up to June 2016 and without specific search criteria for quantitative and mixed methods studies, was presented at the British Thoracic Society in $2016 .^{20}$

\section{Study selection and data extraction}

Search results were screened on titles and abstracts and then on full text by two independent reviewers (FE and IW), gaining consensus on inclusion with input from a referee (JF) if required.

A data extraction form was piloted and two reviewers (FE and IW) independently extracted data from eligible 
papers. Data included study setting, sample size, recruitment method, study design, study objectives, participant/patient characteristics, methods of data collection, data analysis, recorded outcomes, limitations, and conflict of interests. We planned to tabulate data and carry out a meta-analysis using Review Manager ([RevMan], Version 5.3; The Cochrane Collaboration, The Nordic Cochrane Centre, Copenhagen, 2014) statistical software according to our prespecified protocol if this was appropriate.

\section{Quality assessment}

The same reviewers independently appraised study quality to assess the risk of bias in individual studies using the Cochrane Collaboration's tool for assessing risk of bias in RCTs, ${ }^{21}$ the ACROBAT-NRSI (A Cochrane Risk Of Bias Assessment Tool for Non-Randomized Studies of Interventions), ${ }^{22}$ and AMSTAR (A MeaSurement Tool to Assess systematic Reviews $)^{23}$ depending on the type of study.

\section{Results}

Searches identified 5,328 potentially relevant articles of which 14 met our inclusion criteria (Figure 1). All were in English language. Six studies were conducted in the UK, ${ }^{24-29}$ four in Denmark, ${ }^{30-33}$ two in Australia, ${ }^{34,35}$ and one in USA. ${ }^{36}$ One was a systematic review. ${ }^{36}$ Study characteristics and findings are summarized in Table 1.

Ten studies included rates of referral to PR as an outcome $24,25,27-33,36$ of which eight ${ }^{24,27,29-33,36}$ reported the number of patients or patient records studied, in total 44,720. This total included five large audits capturing data from 43,098 patient records (range 1,211-32,018). ${ }^{30-33,36}$ Five studies assessed rates of uptake to PR of which three reported the number of patients studied, in total 1,426 (range 126-600). ${ }^{26,34,35}$ One study reported only percentages. ${ }^{25}$ A systematic review by Jones et $\mathrm{a}^{37}$ found no eligible studies of uptake.

\section{Populations and settings}

Descriptions of patient populations were limited. Age and sex were most commonly reported and no studies reported ethnicity. Age and sex were reported by six studies that measured referral ${ }^{24,27,30-33}$ and three that measured uptake. ${ }^{26,34,35}$ The number and/or roles of clinicians involved were reported by seven studies that measured referral ${ }^{24,25,28,30,31,33,36}$ and two that measured uptake. ${ }^{25,35}$ Overall, patients were older (mean age $\geq 69$ years) and $44 \%-64 \%$ of the samples were males.

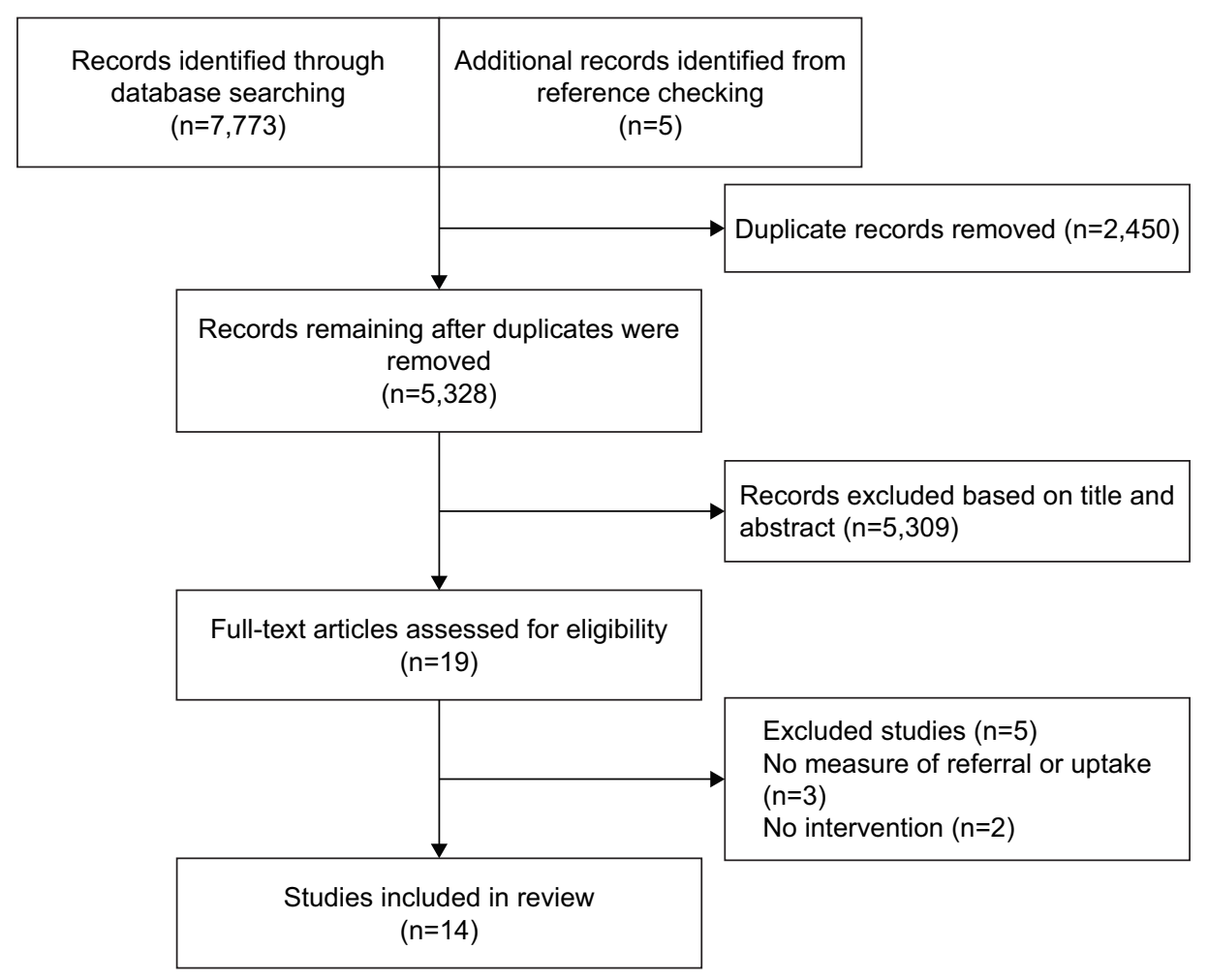

Figure I Study flow diagram. 


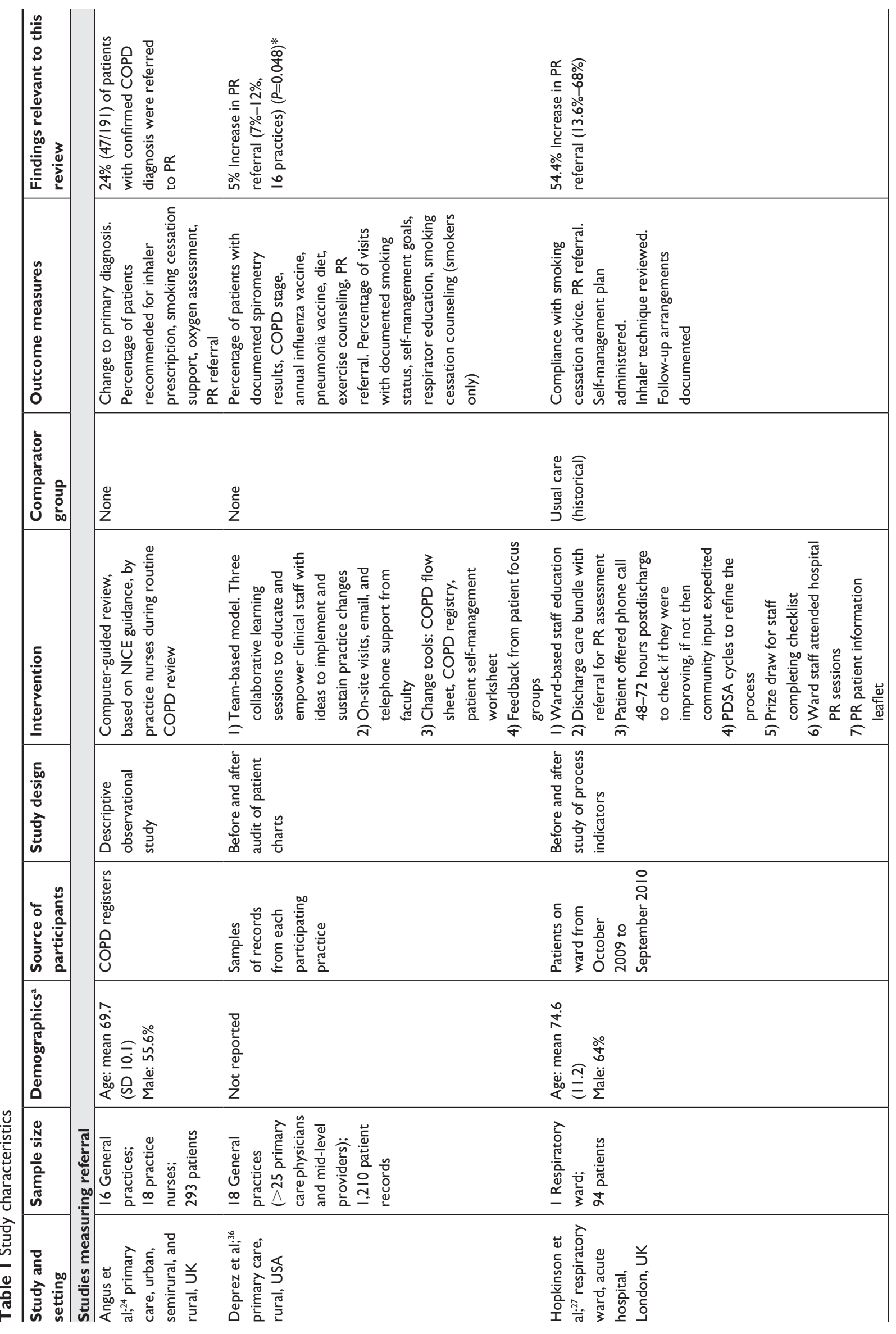




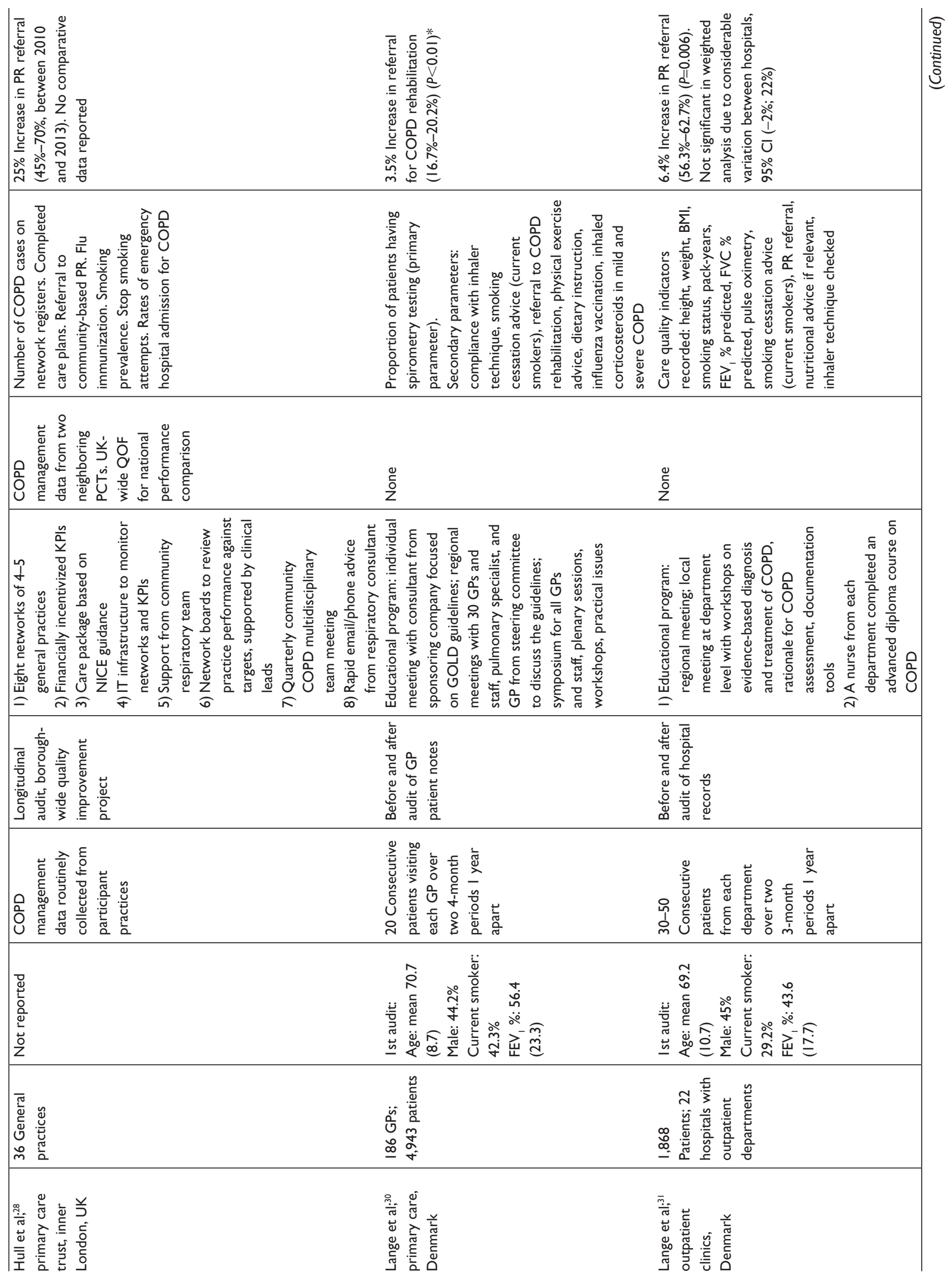




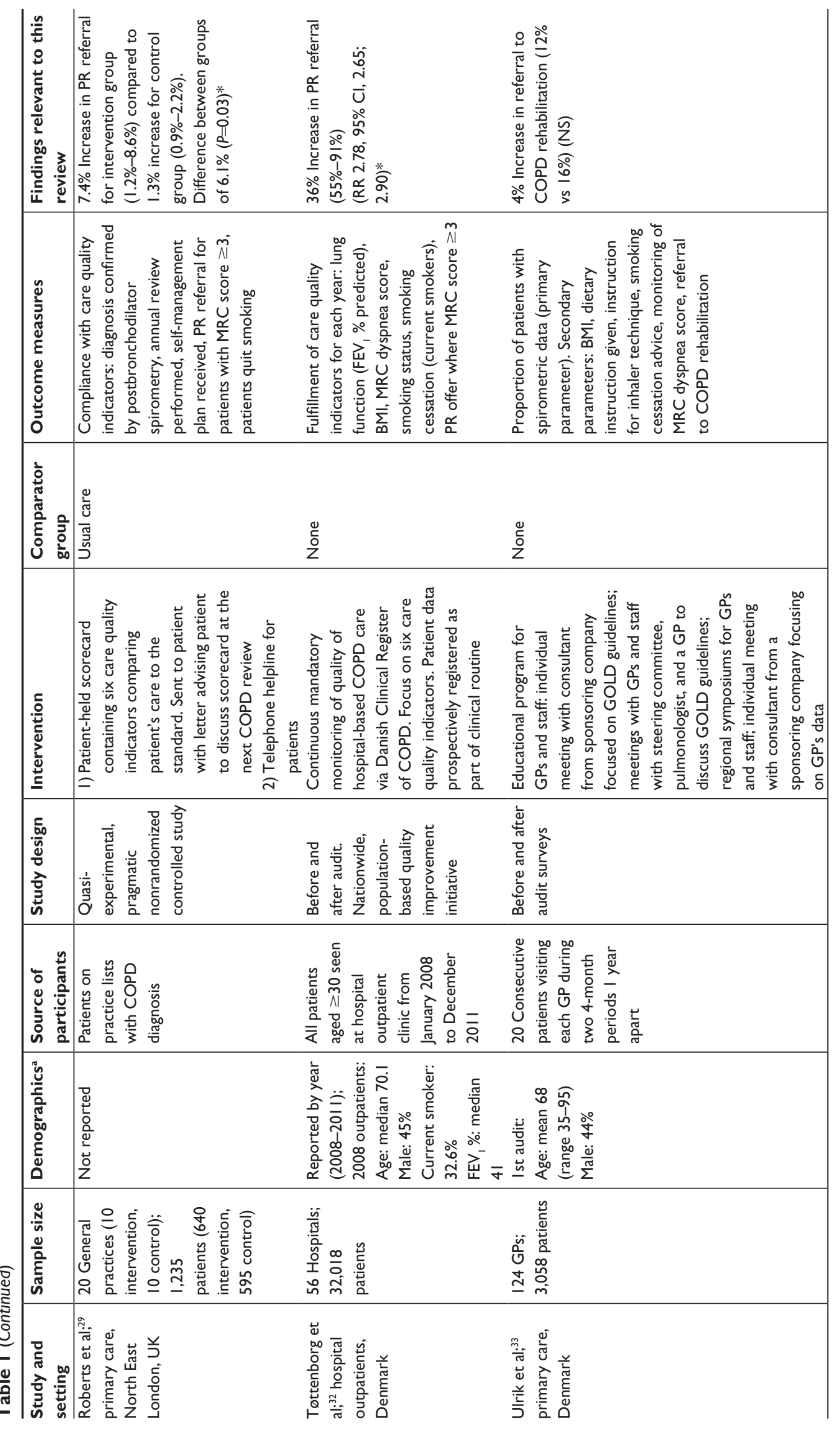




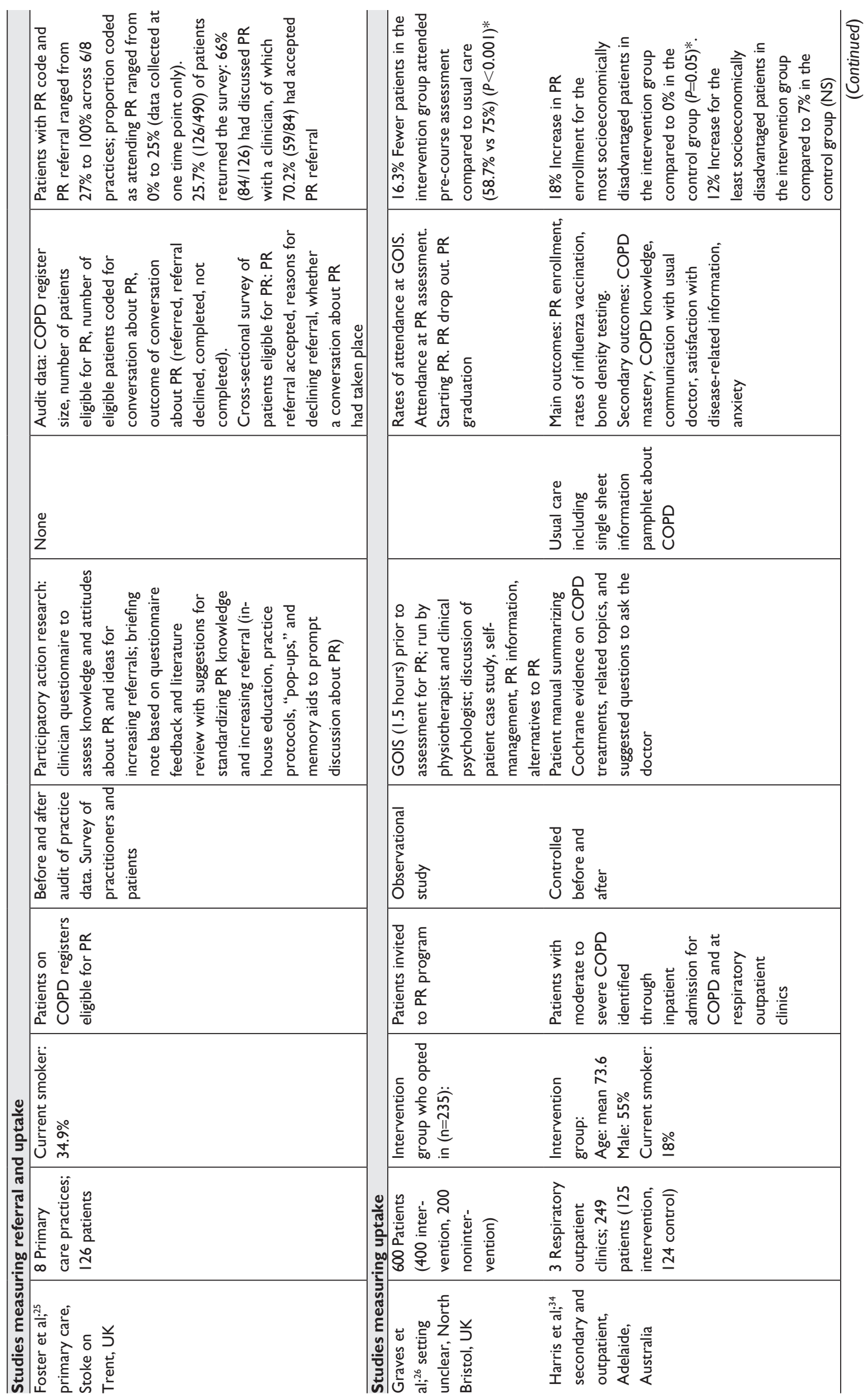




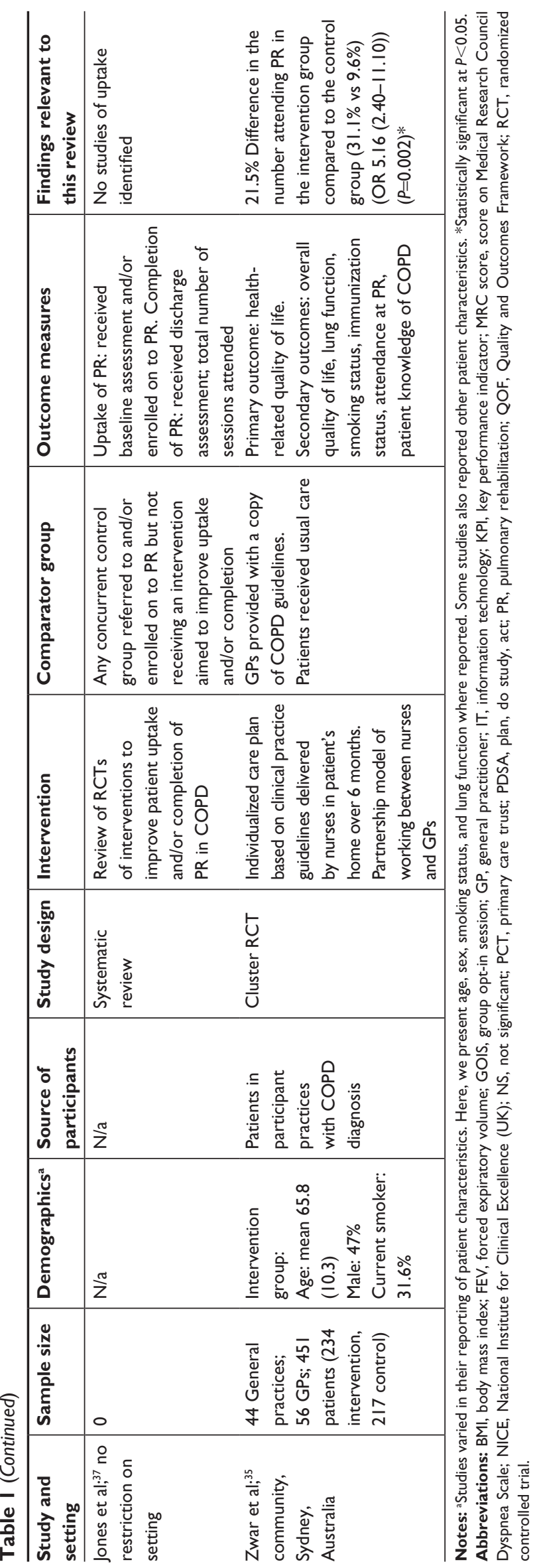

\section{Study designs}

Study designs were heterogeneous and most were observational. Of the referral studies, two captured referral data at one time point only, ${ }^{24,25}$ six reported before and after longitudinal data, ${ }^{28,30-33,36}$ one reported before and after results using a historical comparison group, ${ }^{27}$ and one conducted a pragmatic non-RCT. ${ }^{29}$ Of the uptake studies, one captured uptake data at one time point only, ${ }^{25}$ one reported before and after results using a historical comparison group ${ }^{26}$ one used a controlled before and after design, ${ }^{34}$ and there was one cluster RCT. ${ }^{35}$ The systematic review by Jones et $\mathrm{al}^{37}$ searched for RCTs evaluating uptake and identified none.

\section{Interventions}

Most studies measured referral or uptake to PR in the context of multifaceted evidence-based management of COPD. Only one study focused specifically on referra ${ }^{25}$ and one on uptake. ${ }^{26}$ Interventions ranged from clinician education to system-wide change.

Studies measuring referral in primary care included a computer-guided COPD review, ${ }^{24}$ educational programs for healthcare providers (HCPs), ${ }^{30,33}$ collaborative teambased education and empowerment, ${ }^{36}$ an action research study which generated a range of interventions including education and memory aids, ${ }^{25}$ general practice networks with specialist support and financial incentives, ${ }^{28}$ and a patient-held scorecard comparing the patient's own care against care quality indicators. ${ }^{29}$ Secondary care interventions included education for HCPs,${ }^{31}$ education for HCPs plus a discharge bundle, ${ }^{27}$ and quality monitoring through a clinical register. ${ }^{32}$ Studies measuring uptake included a group opt-in session for patients prior to PR assessment, ${ }^{26}$ a patient-held manual summarizing evidence on COPD treatments with questions to ask the physician, ${ }^{34}$ individualized care planning supported by partnership working between general practitioners (GPs) and nurses,${ }^{34}$ and the action research study by Foster et al..$^{25}$

Referral was reported at the level of individual patients, ${ }^{24}$ practice/department, ${ }^{25,29,36}$ and system level or GP network. ${ }^{28-33}$ Uptake was reported at individual patient levels. ${ }^{26,34,35}$

Table 1 illustrates the range of characteristics of the studies. Primary care was the most common setting. Most interventions targeted clinicians. Patients were targeted in two studies measuring referral ${ }^{27,29}$ and three measuring uptake. ${ }^{26,34,35}$ Two interventions were at the level of healthcare systems, both measuring referral. ${ }^{28,32}$ Education and learning support were the most common features of interventions that targeted clinicians. ${ }^{25,27,30,31,33,36}$ Regarding design, three out of four 
studies measuring uptake had a comparison group design ${ }^{26,34,35}$ compared to three out of 10 measuring referral. ${ }^{27-29}$ All studies of interventions that included elements aimed at patients had a comparison group design. . $6,27,29,34,35$

\section{Outcomes}

Referral to PR was the main outcome in eight out of 10 studies $^{24,25,27-29,31,32,36}$ and uptake was the main outcome in three out of four studies. ${ }^{25,26,34}$ There was limited detail about procedures for data collection. Most referral outcomes were measured by audits of patient records. ${ }^{25,28-33,36}$ Graves et al, ${ }^{26}$ Harris et al, ${ }^{34}$ and Zwar et $\mathrm{al}^{35}$ measured uptake for individual patients though terms such as "enrollment" 34 and "attendance" ${ }^{25}$ were not defined. Foster et $\mathrm{al}^{25}$ asked patients about their decision to attend PR in a survey.

\section{Conflicts of interest}

Potential conflicts of interest were noted in four studies where the authors developed and owned the computer software being assessed ${ }^{24}$ and where consultants from funding organizations were involved in intervention delivery and quality control. ${ }^{30,31,33}$

\section{Assessment of methodological quality of included studies}

All studies had areas of high risk of bias. In the RCT by Zwar et $\mathrm{al}^{35}$ this related to the unavoidable lack of blinding of participants (Table 2). The risk of attrition bias was unclear. Furthermore, 52 out of 234 patients allocated to the intervention group did not receive the intervention. No reasons were given for this and the risk of bias is unclear in this regard (Other bias in Table 2). All remaining studies were considered to have a high risk of bias due to a critical risk of confounding that was associated with the study designs (Table 3 ). The systematic review by Jones et $\mathrm{al}^{37}$ was of high methodological quality (Table 4).

\section{Study findings}

Due to study heterogeneity, we considered it inappropriate to summarize results using a meta-analysis. The reported outcomes can only be understood in the context of each study and are not readily comparable across studies. Furthermore, when considering the study outcomes in light of the various characteristics shown in Table 5 there were no discernible patterns to link study characteristics and outcomes.

\section{Referral to PR}

Four studies reported statistically significant increases in PR referral. In primary care, Roberts et $\mathrm{al}^{29}$ reported an increase for the intervention group following use of a patient-held quality scorecard, which was $6.1 \%(P=0.03)$ greater than that for the control group. Following a collaborative model of education and change implementation, mean referral to PR across 16 general practices increased by $5 \%$ (from $7 \%$ to $12 \%)(P=0.048),{ }^{36}$ and a $3.5 \%$ increase in referrals (from $16.7 \%$ to $20.2 \%)(P<0.01)$ followed an education program in primary care. ${ }^{30}$ Tøttenborg et $\mathrm{al}^{32}$ reported a $36 \%$ increase in referrals (from $55 \%$ to $91 \%$ ) (relative risk $2.78,95 \%$ CI, 2.65; 2.90) across hospital outpatient departments during mandatory monitoring of quality indicators.

Positive but statistically nonsignificant results followed an educational program in primary care ${ }^{33}$ and an education program across outpatient departments. ${ }^{31}$ Two studies reported increases based on descriptive data following use of a COPD discharge care bundle in a hospital ward ${ }^{27}$ and a quality improvement intervention across primary care. ${ }^{28}$ A computer-guided COPD review ${ }^{24}$ and an action research study $^{25}$ did not collect comparative data.

\section{Uptake of PR}

Two studies reported statistically significant increases in uptake. Harris et $\mathrm{al}^{34}$ evaluated a patient manual summarizing evidence on COPD treatments and reported an increase of $18 \%$ in PR enrollment among participants in the most socioeconomically disadvantaged stratum compared to no increase in the matched control group $(P=0.05)$. Zwar et $\mathrm{al}^{35}$ reported a $21.5 \%$ difference in the number of intervention group patients attending PR $(P=0.002)$ compared to controls where the intervention group had received an individualized care plan supported by partnership working between nurses and GPs.

Table 2 Risk of bias assessment (Cochrane RCT) for randomized studies

\begin{tabular}{|c|c|c|c|c|c|c|c|}
\hline Study & $\begin{array}{l}\text { Random } \\
\text { sequence } \\
\text { generation } \\
\text { (selection bias) }\end{array}$ & $\begin{array}{l}\text { Allocation } \\
\text { concealment } \\
\text { (selection } \\
\text { bias) }\end{array}$ & $\begin{array}{l}\text { Blinding of } \\
\text { participants } \\
\text { and personnel } \\
\text { (performance bias) }\end{array}$ & $\begin{array}{l}\text { Incomplete } \\
\text { outcome } \\
\text { data (attrition } \\
\text { bias) }\end{array}$ & $\begin{array}{l}\text { Blinding of } \\
\text { outcome } \\
\text { assessment } \\
\text { (detection bias) }\end{array}$ & $\begin{array}{l}\text { Selective } \\
\text { reporting } \\
\text { (reporting } \\
\text { bias) }\end{array}$ & Other bias \\
\hline Zwar et $\mathrm{al}^{35}$ & Low & Low & High & Unclear & Low & Low & Unclear \\
\hline
\end{tabular}

Abbreviation: RCT, randomized controlled trial. 
Table 3 Cochrane Risk of Bias Assessment Tool for nonrandomized studies of interventions (ACROBAT-NRSI)

\begin{tabular}{|c|c|c|c|c|c|c|c|}
\hline Study & $\begin{array}{l}\text { Bias due to } \\
\text { confounding }\end{array}$ & $\begin{array}{l}\text { Bias in } \\
\text { selection of } \\
\text { participants } \\
\text { into the study }\end{array}$ & $\begin{array}{l}\text { Bias in } \\
\text { measurement } \\
\text { of interventions }\end{array}$ & $\begin{array}{l}\text { Bias due to } \\
\text { departures } \\
\text { from intended } \\
\text { interventions }\end{array}$ & $\begin{array}{l}\text { Bias due } \\
\text { to missing } \\
\text { data }\end{array}$ & $\begin{array}{l}\text { Bias in } \\
\text { measurement } \\
\text { of outcomes }\end{array}$ & $\begin{array}{l}\text { Bias in selection } \\
\text { of the reported } \\
\text { results }\end{array}$ \\
\hline Angus et $\mathrm{al}^{24}$ & Critical & Serious & Serious & Serious & Serious & Moderate & Moderate \\
\hline Deprez et $\mathrm{al}^{36}$ & Critical & Serious & Low & No information & Moderate & Moderate & Low \\
\hline Foster et $\mathrm{al}^{25}$ & Critical & Serious & Serious & Serious & Serious & Moderate & Moderate \\
\hline Graves et $\mathrm{al}^{26}$ & Critical & Low & Low & Serious & Low & Moderate & Moderate \\
\hline Harris et $\mathrm{al}^{34}$ & Critical & Serious & Low & Moderate & Moderate & Moderate & Moderate \\
\hline Hopkinson et $\mathrm{al}^{27}$ & Critical & Serious & Low & Serious & Low & Moderate & Moderate \\
\hline Hull et $\mathrm{al}^{28}$ & Critical & Moderate & Serious & Moderate & Low & Moderate & Moderate \\
\hline Lange et $\mathrm{al}^{30}$ & Critical & Serious & Low & Moderate & Moderate & Moderate & Moderate \\
\hline Lange et $\mathrm{al}^{31}$ & Critical & Serious & Low & Moderate & Moderate & Moderate & Moderate \\
\hline Roberts et $\mathrm{al}^{29}$ & Critical & Serious & Low & Moderate & Moderate & Moderate & Moderate \\
\hline Tøttenborg et $\mathrm{al}^{32}$ & Critical & Low & Low & Moderate & Moderate & Moderate & Moderate \\
\hline Ulrik et $\mathrm{al}^{33}$ & Critical & Serious & Low & Moderate & Moderate & Moderate & Moderate \\
\hline
\end{tabular}

One study did not collect comparative data ${ }^{25}$ and a statistically significant decrease in uptake followed a group opt-in patient information session compared to usual care (58.7\% vs $75 \%, P<0.001){ }^{26}$

\section{Discussion}

Our carefully conducted systematic review identified a heterogeneous group of studies. Most reported some positive results but only six out of 14 demonstrated statistically significant improvements. Statistically significant increases in referral followed educational sessions for clinicians in primary care, ${ }^{30}$ collaborative learning sessions for $\mathrm{HCPs},{ }^{36}$ use of a patient-held COPD care scorecard in primary care, ${ }^{29}$ and continuous monitoring of care quality indicators in hospital settings. ${ }^{32}$ Statistically significant increases in uptake followed use of a patient-held summary of COPD research

Table 4 Quality assessment of Jones et al ${ }^{37}$ against the AMSTAR (A MeaSurement Tool to Assess systematic Reviews) measurement tool"

\begin{tabular}{l|l}
\hline Was an "a priori" design provided? & Yes \\
Was there duplicate study selection and data extraction? & Yes \\
Was a comprehensive literature search performed? & Yes \\
Was the status of publication (ie, gray literature) used as an & Yes \\
inclusion criterion? & \\
Was a list of studies (included and excluded) provided? & Yes \\
Were the characteristics of the included studies provided? & Yes \\
Was the scientific quality of the included studies assessed and & Yes \\
documented? & \\
Was the scientific quality of the included studies used & Yes \\
appropriately in formulating conclusions? & \\
Were the methods used to combine the findings of studies & N/a \\
appropriate? & Yes \\
Was the likelihood of publication bias assessed? & Yes \\
Was the conflict of interest stated?
\end{tabular}

evidence in secondary care ${ }^{34}$ and a nurse/GP partnership model of care ${ }^{35}$ Significantly fewer patients who attended a group opt-in information session subsequently attended PR assessment compared to patients for whom no opt-in session was offered, although subsequent completion rates improved among those who attended. ${ }^{26}$ Only three studies focused specifically on referral ${ }^{25}$ or uptake $e^{26,37}$ and we are unable to accurately evaluate the impact of a targeted approach to increase referral or uptake to PR.

The potential for generalizability from the studies is limited by four factors. Firstly, most study designs carried areas of high risk of bias. Secondly, some interventions were not well defined. For example, in two studies the terms "enrollment" 34 and "attendance" ${ }^{35}$ were not explained and it was not possible to distinguish between attendance at precourse assessment and the first PR class, which are separate stages in the PR pathway. Thirdly, there was limited reporting of patient and clinician populations which may be potentially nonrepresentative. Fourthly, the studies were conducted in high income countries and there were no interventions in low-to-middle income countries where over $90 \%$ of deaths globally from COPD occur. ${ }^{2}$

Two of the studies performed spirometry and confirmed a COPD diagnosis in $57.8 \%{ }^{35}$ and $81 \%{ }^{24}$ of patients. Jones et $\mathrm{al}^{37}$ included only participants with a diagnosis of COPD confirmed by spirometry in their systematic review and identified no studies of uptake. Evidence shows that patients on COPD registers do not always have a confirmed diagnosis with proportions varying from $73 \%{ }^{38}$ to $90 \%{ }^{39}$ The question remains as to whether this is problematic for drawing conclusions from intervention studies. If studies do not confirm a COPD diagnosis it is possible that the COPD population 


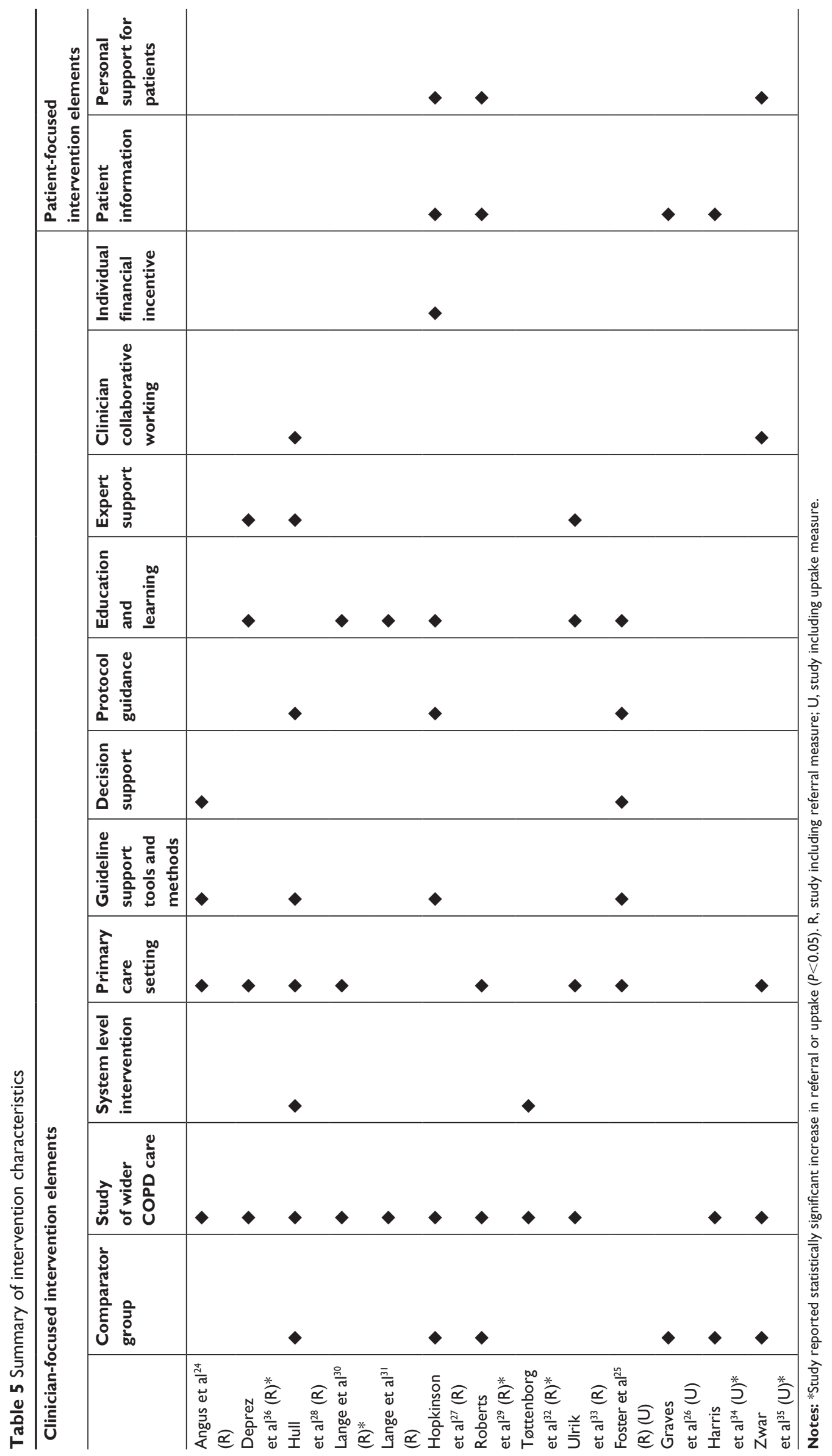


is overestimated and that effect sizes are therefore over or underestimated. However, Zwar et $\mathrm{al}^{35}$ provided a pragmatic argument for including patients with a clinical diagnosis of COPD that did not require confirmation by spirometry, indicating that this reflects practice in primary care, where diagnosis is often made and treatment initiated on clinical grounds.

\section{Strengths and limitations}

Strengths of this review are the use of recognized systematic methods and a search without language or date restriction, which reduced the risk of bias in conducting the review. A limitation is that it was not possible to verify the content of the reported PR programs to ensure that they matched the definition adopted for this review. ${ }^{18}$ Due to heterogeneity among the studies and poor quality assessments relative to evidence-based medicine quality criteria it is not possible to provide clear evidence-based recommendations for practice. The scope of this review, inclusive of different study designs, provides a novel and broad insight into the extent and type of evidence in the field and can provide a useful stimulus for intervention developers and researchers.

\section{Comparison with other studies}

Our review supplements that of Jones et $\mathrm{al}^{37}$ by including a broad range of study designs and not requiring spirometryconfirmed diagnosis. A Cochrane review of referral, uptake, and adherence to PR has been registered recently and will add knowledge to this field. ${ }^{40}$

Whilst we cannot draw clear conclusions from our review about the efficacy of the interventions to increase referral and uptake to PR, these studies do address some of the known barriers and facilitators to referral and uptake.

Referral is impacted by accessibility of PR programs, HCPs' knowledge of who and how to refer, the administrative burden of making a referral, successful previous referral of other patients, the influence of the referring doctor (either positive or negative), and by patients knowing what PR involves and how it will help their health. ${ }^{41}$ Interventions in this review supported clinicians through education and guidance to improve their knowledge of referral and PR, ${ }^{24,25,27,28,30,31,33,36}$ use of reminders and prompts, ${ }^{24,25}$ and the inclusion of PR referral in a discharge care bundle. ${ }^{27}$ Education and learning support were the most common features of interventions directly targeting clinicians though it is unclear whether the education programs addressed the nature of the conversation between the HCP and the patient about PR referral or supported clinician skills in this regard. None of the interventions addressed accessibility of PR programs and it can only be assumed that sufficient capacity was available.

Barriers to patient uptake include transport and location, ${ }^{42-44}$ inconvenient timing, ${ }^{42,44}$ disruption to routine/ other priorities, ${ }^{41-43}$ influence of the referring doctor, ${ }^{42}$ lack of explanation of benefits, ${ }^{44}$ lack of perceived benefit, ${ }^{41,42,44}$ believing oneself to be too disabled ${ }^{44}$ or that one's conditions is not serious enough, ${ }^{41,44}$ negative past experience with PR or exercise, ${ }^{44}$ and burden of COPD and other health conditions. ${ }^{41}$ Reasons for attending include a trusted, enthusiastic doctor who explained the benefits, perceived increased severity of the condition, perceiving that PR would help increase control and independence and improve health, and perceived social benefits. ${ }^{44}$ Positive reinforcement of PR by HCPs during the referral process is important. ${ }^{41}$ The study by Zwar et al, ${ }^{35}$ in which attendance at PR increased, provided individualized care plans and nurse support in patients' homes, a model which could accommodate a personalized discussion over time about the benefits of PR to the patient and presumably establish a trusting relationship. However, Zwar et $\mathrm{al}^{35}$ noted that although more patients in the intervention group attended PR this was still less than a third of the group. Interestingly, the information session provided in the study by Graves et al, ${ }^{26}$ which informed patients about the benefits of PR, was associated with reduced attendance at assessment but did improve attendance of those who started PR. Whilst perhaps not providing motivational support for patients who were unsure about attending, it could nevertheless improve service efficiency and highlights the importance of considering the whole PR pathway. The manual of COPD evidence-based treatments provided by Harris et $\mathrm{al}^{34}$ was helpful for more socioeconomically disadvantaged patients and may have facilitated a constructive clinician-patient interaction for this group. The authors also noted that more patients in this group reported actually using the manual, which would clearly influence any impact assessment. This highlights the need for good understanding of how interventions work as well as whether they work. Practical factors such as transport, travel, and timing were not addressed by the interventions.

Strategies to improve referral and uptake have also been studied in cardiac rehabilitation (CR) with some success. A systematic review of interventions to promote uptake and adherence in CR reported improvements in eight out of 10 studies of uptake but, as in our review, the authors could not make clear practice recommendations due to heterogeneity and risk of bias in the studies. ${ }^{45}$ Another systematic review of interventions around referral and uptake to CR found 11 
studies of referral and 13 studies of enrollment in the US, Canada, and the UK. ${ }^{46}$ The highest rates of referral (up to $85 \%$ ) were found in studies that implemented automatic referral orders (eg, from healthcare records or data) whereas the highest rates of enrollment (up to 86\%) were achieved with a combination of automatic and liaison methods, including discussion with an HCP. Enrollment and uptake to CR can also be improved by referral and structured follow-up by nurses or therapists and early outpatient education. ${ }^{45,47,48}$ Whether findings from CR might be translated to PR is worthy of further research. The rehabilitation pathway differs for CR because referrals typically occur at the time of hospitalization for an acute event or procedure, whereas in the UK, for example, most PR referrals occur in primary care at the time of stable disease. ${ }^{13}$

\section{Implications for practice and research}

There is a call to provide recommendations to increase the delivery of PR worldwide to validate novel techniques for doing so, and to enhance evidence-based policy. ${ }^{12}$ While more evidence is needed to establish the efficacy and effectiveness of different approaches, the studies reviewed here provide a useful platform for further work. The variety of interventions they represent, from one-off information sessions to system-wide improvement projects, reflects the complex nature of COPD care management and the potential value of a range of evidence building approaches.

Firstly, there is an urgent need for high quality study designs to determine the efficacy, effectiveness, and causal mechanisms of interventions. There is a lack of evidence from RCTs and we identified only one ongoing RCT to test a method not previously evaluated: a video to increase PR uptake following hospitalized exacerbations of COPD. ${ }^{49}$ Whilst RCTs are the gold standard for establishing a generalizable evidence base, they may not be the only relevant evaluation design in this field. There is a need to recognize contextual factors and the diversity of PR delivery and settings across the world.$^{50}$ In this regard, quality improvement approaches are well suited to learn what works in a local context, particularly where rapid testing of novel interventions is needed. In contrast to research methods which aim to generate new knowledge, the aim of these approaches is to achieve positive and practical change in an identified service through focus on a well-defined problem. ${ }^{51}$ These methods are accessible to service providers in "real-world" settings. Two studies reviewed here, Hull et $\mathrm{al}^{28}$ and Hopkinson et al, ${ }^{27}$ utilized quality improvement methods. In addition, for the researcher, realist approaches that seek to identify what works, in which circumstances, and for whom could help to recognize and accommodate contextual complexity within the evaluation design and provide more transferable learning about the impact of contextual factors. ${ }^{52}$ Such methods have value in real-world settings where multiple variables cannot be controlled.

Secondly, there is a need to improve reporting of study populations as a factor to enhance external validity. Results from Harris et $\mathrm{al}^{34}$ suggest differential effects across subgroups of patients and this is worthy of further investigation. None of the studies in this review reported the ethnicity of patients. In an area of East London in the UK members of some Black and minority ethnic populations have lower rates of referral to PR compared to White patients ${ }^{53}$ and there is a need to understand more about how to support PR access in ethnically diverse communities. There may also be specific issues in resource poor countries ${ }^{54}$ which are not represented among the studies in this review.

Thirdly, in their study of a group opt-in session prior to assessment, Graves et $\mathrm{a}^{26}$ reported that, despite no impact on uptake, fewer intervention patients who started PR dropped out for reasons other than illness and significantly more graduated. This indicates the importance of considering the whole PR pathway. Following the patient through the entirety of their PR journey will lead to a greater understanding of how to improve service efficiency. Only two studies in this review intervened at the system level ${ }^{28,32}$ and there is scope for more research in this area. More studies measured referral than uptake and more patients were included in referral studies than in uptake studies, suggesting a differential focus on these two stages.

Fourthly, interventions may benefit from theory-based design. Cox et $\mathrm{al}^{41}$ used the Theoretical Domains Framework to analyze factors affecting referral and participation in PR and we have highlighted above how some of the reviewed studies addressed these factors, although it was not possible to asses this accurately without access to more detailed intervention descriptions. However, we believe that the work by Cox et $\mathrm{al}^{41}$ provides a useful theoretical framework for intervention designers. Interventions could focus on specific constructs that have been shown to have relevance and then assess the impact on those constructs to generate a theoretically informed understanding of what works and why.

\section{Conclusion}

This review demonstrates the broad range of approaches aimed at increasing referral and uptake to PR across primary 
and secondary care. Some positive results have been demonstrated but there is limited generalizable evidence because interventions and methods are heterogeneous and descriptions of populations are limited. Further theory-based testing of promising interventions using robust methods in various populations and settings is required to draw clear conclusions about how to optimize access to PR across a range of settings.

\section{Acknowledgment}

Delivery of this work was supported by the Cambridge Biomedical Research Centre.

\section{Author contributions}

JF, FE, IW, and CD conceived and designed the review. IK provided expert support and conducted the literature search. FE and IW reviewed the titles and abstracts, selected the papers, and extracted and analyzed the data. All authors were involved in drafting and revision of the manuscript for important intellectual content and approved the final version to be published. All authors agree to be accountable for aspects of the work. JF is the guarantor of the paper.

\section{Disclosure}

The authors report no conflicts of interest in this work.

\section{References}

1. López-Campos JL, Tan W, Soriano JB. Global burden of COPD. Respirology. 2016;21(1):14-23.

2. World Health Organisation. [updated 2018]. Available from: http:// www.who.int/respiratory/copd/burden/en/. Accessed April 19, 2018.

3. British Lung Foundation. Chronic obstructive pulmonary disease (COPD) statistics. Available from: http://statistics.blf.org.uk/copd. Accessed April 19, 2018.

4. NHS Medical Directorate. COPD Commissioning Toolkit. 2012. Available from: https://assets.publishing.service.gov.uk/government/ uploads/system/uploads/attachment_data/file/212876/chronic-obstructive-pulmonary-disease-COPD-commissioning-toolkit.pdf. Accessed September 25, 2018.

5. Mccarthy B, Casey D, Devane D, Murphy K, Murphy E, Lacasse Y. Pulmonary rehabilitation for chronic obstructive pulmonary disease (Review). Cochrane Database Syst Rev. 2015;2:CD003793.

6. Steiner M, McMillan V, Lowe D. Pulmonary rehabilitation: beyond breathing better. National Chronic Obstructive Pulmonary Disease (COPD) Audit Programme: outcomes from the clinical audit of pulmonary rehabilitation services in England 2015. London: RCP; 2017.

7. Seymour JM, Moore L, Jolley CJ, et al. Outpatient pulmonary rehabilitation following acute exacerbations of COPD. Thorax. 2010;65(5):423-428.

8. Singh SJ, Zuwallack RL, Garvey C, Spruit MA. American Thoracic Society/European Respiratory Society Task Force on Pulmonary Rehabilitation. Learn from the past and create the future: the 2013 ATS/ERS statement on pulmonary rehabilitation. Eur Respir J. 2013;42(5):1169-1174.

9. Griffiths TL, Phillips CJ, Davies S, Burr ML, Campbell IA. Cost effectiveness of an outpatient multidisciplinary pulmonary rehabilitation programme. Thorax. 2001;56(10):779-784.

10. Bolton CE, Bevan-Smith EF, Blakey JD, et al. British Thoracic Society guideline on pulmonary rehabilitation in adults. Thorax. 2013; 68(Suppl 2):1-30.
11. Spruit MA, Singh SJ, Garvey C, et al. An official American Thoracic Society/European Respiratory Society statement: key concepts and advances in pulmonary rehabilitation. Am J Respir Crit Care Med. 2013; 188(8):e13-e15.

12. Vogiatzis I, Rochester CL, Spruit MA, Troosters T, Clini EM. American Thoracic Society/European Respiratory Society Task Force on Policy in Pulmonary Rehabilitation. Increasing implementation and delivery of pulmonary rehabilitation: key messages from the new ATS/ERS policy statement. Eur Respir J. 2016;47(5):1336-1341.

13. Steiner M, Holzhauer-Barrie J, Lowe D, et al. Pulmonary rehabilitation: time to breathe better. National Chronic Obstructive Pulmonary Disease (COPD) Audit Programme: resources and organisation of pulmonary rehabilitation services in England and Wales 2015. National organisational audit report. London: RCP; 2015.

14. Jongepier L, Barlow R. Pulmonary rehabilitation (PR) capacity, uptake and completion rate in the East of England. Eur Respir J. 2016;48(Supp1 60):3584.

15. Higgins JPT, Green S (editors). Cochrane Handbook for Systematic Reviews of Interventions version 5.1.0 [updated March 2011]. London: The Cochrane Collaboration; 2011. Available from: http://handbook. cochrane.org. Accessed April 24, 2018.

16. Early F, Wellwood I, Kuhn I, Deaton C, Fuld J. A systematic review of literature on interventions to increase referral to and uptake of pulmonary rehabilitation programmes in people with chronic obstructive pulmonary disease (COPD). 2016. PROSPERO 2016 CRD42016043762. Available from: http://www.crd.york.ac.uk/PROSPERO/display_record. php?ID=CRD42016043762. Accessed April 24, 2018.

17. Liberati A, Altman DG, Tetzlaff J, et al. The PRISMA statement for reporting systematic reviews and meta-analyses of studies that evaluate healthcare interventions: explanation and elaboration. BMJ. 2009; 339:b2700.

18. National Institute for Health and Clinical Excellence. Chronic obstructive pulmonary disease in over 16s: diagnosis and management. Clinical guideline CG101. 2010. Available from: http://www.nice.org.uk/ guidance/cg101. Accessed April 24, 2018.

19. Strings attached: Strings attached: CADTH database search filters [Internet]. Ottawa: CADTH; 2016. Available from: https://www.cadth. $\mathrm{ca} /$ resources/finding-evidence/strings-attached-cadths-database-searchfilters. Accessed September 25, 2018.

20. Early F, Wellwood I, Kuhn I, et al. P212 Interventions to increase referral to and uptake of pulmonary rehabilitation programmes for people with chronic obstructive pulmonary disease (COPD): a systematic review. Thorax. 2016;71(Suppl 3):A200-A201.

21. Higgins JPT, Altman DG, Gøtzsche PC, et al. The Cochrane Collaboration's tool for assessing risk of bias in randomised trials. BMJ. 2011;343:d5928.

22. Sterne JAC, Higgins JPT, Reeves BC on behalf of the development group for ACROBAT-NRSI. A Cochrane Risk Of Bias Assessment Tool: for Non-Randomized Studies of Interventions (ACROBATNRSI), Version 1.0.0, 24 September 2014. Available from: http:// www.bristol.ac.uk/population-health-sciences/centres/cresyda/barr/ riskofbias/robins-i/acrobat-nrsi/. Accessed September 25, 2018.

23. Shea BJ, Grimshaw JM, Wells GA, et al. Development of AMSTAR: a measurement tool to assess the methodological quality of systematic reviews. BMC Med Res Methodol. 2007;7(1):10.

24. Angus RM, Thompson EB, Davies L, et al. Feasibility and impact of a computer-guided consultation on guideline-based management of COPD in general practice. Prim Care Respir J. 2012;21(4):425-430.

25. Foster F, Piggott R, Riley L, Beech R. Working with primary care clinicians and patients to introduce strategies for increasing referrals for pulmonary rehabilitation. Prim Health Care Res Dev. 2016;17(3): 226-237.

26. Graves J, Sandrey V, Graves T, Smith DL. Effectiveness of a group opt-in session on uptake and graduation rates for pulmonary rehabilitation. Chron Respir Dis. 2010;7(3):159-164.

27. Hopkinson NS, Englebretsen C, Cooley N, et al. Designing and implementing a COPD discharge care bundle. Thorax. 2012;67(1):90-92. 
28. Hull S, Mathur R, Lloyd-Owen S, Round T, Robson J. Improving outcomes for people with COPD by developing networks of general practices: evaluation of a quality improvement project in east London. NPJ Prim Care Respir Med. 2014;24(1):14082.

29. Roberts CM, Gungor G, Parker M, Craig J, Mountford J. Impact of a patient-specific co-designed COPD care scorecard on COPD care quality: a quasi-experimental study. NPJ Prim Care Respir Med. 2015; 25(1):15017.

30. Lange P, Rasmussen FV, Borgeskov H, et al. The quality of COPD care in general practice in Denmark: the KVASIMODO study. Prim Care Respir J. 2007;16(3):174-181.

31. Lange P, Andersen KK, Munch E, et al. Quality of COPD care in hospital outpatient clinics in Denmark: the KOLIBRI study. Respir Med. 2009;103(11):1657-1662.

32. Tøttenborg SS, Thomsen RW, Nielsen H, Johnsen SP, Frausing Hansen E, Lange P. Improving quality of care among COPD outpatients in Denmark 2008-2011. Clin Respir J. 2013;7(4):319-327.

33. Ulrik CS, Hansen EF, Jensen MS, et al. Management of COPD in general practice in Denmark - participating in an educational program substantially improves adherence to guidelines. Int J COPD. 2010;5: 73-79.

34. Harris M, Smith BJ, Veale AJ, Esterman A, Frith PA, Selim P. Providing reviews of evidence to COPD patients: controlled prospective 12-month trial. Chron Respir Dis. 2009;6(3):165-173.

35. Zwar NA, Hermiz O, Comino E, et al. Care of patients with a diagnosis of chronic obstructive pulmonary disease: a cluster randomised controlled trial. Med J Aust. 2012;197(7):394-398.

36. Deprez R, Kinner A, Millard P, Baggott L, Mellett J, Loo JL. Improving quality of care for patients with chronic obstructive pulmonary disease. Popul Health Manag. 2009;12(4):209-215.

37. Jones AW, Taylor A, Gowler H, O’Kelly N, Ghosh S, Bridle C. Systematic review of interventions to improve patient uptake and completion of pulmonary rehabilitation in COPD. ERJ Open Res. 2017;3(1):000892016.

38. Jones RCM, Dickson-Spillmann M, Mather MJC, Marks D, Shackell BS Accuracy of diagnostic registers and management of chronic obstructive pulmonary disease: the Devon primary care audit. Respir Res. 2008; 9(1):62.

39. Baxter N, Holzhauer-Barrie J, McMillan V, Saleem Khan M, Skipper E, Roberts CMI. Time to take a breath. National Chronic Obstructive Pulmonary Disease (COPD) Audit Programme: clinical audit of COPD in primary care in Wales 2014-2015. National clinical audit report. London: RCP; 2016.

40. Young J, Jordan RE, Adab P, Enocson A, Jolly K. Interventions to promote referral, uptake and adherence to pulmonary rehabilitation for people with chronic obstructive pulmonary disease (COPD) (protocol). Cochrane Database Syst Rev. 2017;10:CD012813.
41. Cox NS, Oliveira CC, Lahham A, Holland AE. Pulmonary rehabilitation referral and participation are commonly influenced by environment, knowledge, and beliefs about consequences: a systematic review using the Theoretical Domains Framework. J Physiother. 2017;63(2): 84-93.

42. Keating A, Lee A, Holland AE. What prevents people with chronic obstructive pulmonary disease from attending pulmonary rehabilitation? A systematic review. Chron Respir Dis. 2011;8(2):89-99.

43. Mathar H, Fastholm P, Hansen IR, Larsen NS. Why do patients with COPD decline rehabilitation. Scand J Caring Sci. 2016;30(3) $432-441$.

44. Sohanpal R, Steed L, Mars T, Taylor SJC. Understanding patient participation behaviour in studies of COPD support programmes such as pulmonary rehabilitation and self-management: a qualitative synthesis with application of theory. NPJ Prim Care Respir Med. 2015;25(1):15054.

45. Karmali KN, Davies P, Taylor F, Beswick A, Martin N, Ebrahim S. Promoting patient uptake and adherence in cardiac rehabilitation. Cochrane Database Syst Rev. 2014;6:CD007131.

46. Gravely-Witte S, Leung YW, Nariani R, et al. Effects of cardiac rehabilitation referral strategies on referral and enrollment rates. Nat Rev Cardiol. 2010;7(2):87-96.

47. Clark AM, King-Shier KM, Duncan A, et al. Factors influencing referral to cardiac rehabilitation and secondary prevention programs: a systematic review. Eur J Prev Cardiol. 2013;20(4):692-700.

48. Grace SL, Angevaare KL, Reid RD, et al. Effectiveness of inpatient and outpatient strategies in increasing referral and utilization of cardiac rehabilitation: a prospective, multi-site study. Implement Sci. 2012;7(1):120.

49. Jones S. 2015. Video to increase rehabilitation uptake following hospitalised exacerbations of COPD: a randomised controlled trial. ISRCTN Available from: http://www.isrctn.com/ISRCTN13165073. Accessed October 02, 2018.

50. Spruit MA, Pitta F, Garvey C, et al. Differences in content and organisational aspects of pulmonary rehabilitation programmes. Eur Respir J. 2014;43(5):1326-1337.

51. Portela MC, Pronovost PJ, Woodcock T, Carter P, Dixon-Woods M. How to study improvement interventions: a brief overview of possible study types. BMJ Qual Saf. 2015;24(5):325-336.

52. Pawson R, Tilley N. Realistic Evaluation. London: Sage; 2013

53. Martin A, Badrick E, Mathur R, Hull S. Effect of ethnicity on the prevalence, severity, and management of COPD in general practice. Br J Gen Pract. 2012;62(595):e76-e81.

54. Desalu OO, Onyedum CC, Adeoti AO, et al. Guideline-based COPD management in a resource-limited setting - physicians' understanding, adherence and barriers: a cross-sectional survey of internal and family medicine hospital-based physicians in Nigeria. Prim Care Respir J. 2013;22(1):79-85. 


\section{Supplementary material}

MEDLINE search strategy

1 (((pulmonary rehabilitation.ti,ab.) or (((emphysema or copd or chronic obstructive pulmonary disease or chronic bronchitis or chronic asthma).ti,ab. or exp Pulmonary Disease, Chronic Obstructive/ or exp Bronchitis, Chronic/ or exp Asthma/ or exp Emphysema/) and ((exercis* or rehab* or physiotherap* or "physical therap*").ti,ab. or exp Exercise Therapy/ or exp Exercise/ or exp rehabilitation/ or exp Physical Therapy Modalities/))) and ((refer* 1 or referring or referred or referral* or assess*).ti,ab. Or exp "Referral and Consultation") And ((rate* or number* or audit* or percentage or barrier* or facilitat* or frequen* or infrequent* or rare* or common* or uncommon or standard* or influenc* or reluctant* or barrier* or obstacle or (meet* adj3 criter*)).ti,ab. Or exp practice patterns, physicians/ or exp guideline adherence or exp data collection/))

2 ((pulmonary rehabilitation.ti,ab.) or (((emphysema or copd or chronic obstructive pulmonary disease or chronic bronchitis).ti,ab. or exp Pulmonary Disease, Chronic Obstructive/ or exp Bronchitis, Chronic/ or exp Emphysema/) and ((exercis* or rehab* or physiotherap* or "physical therap*").ti,ab. or exp Exercise Therapy/ or exp Exercise/ or exp rehabilitation/ or exp Physical Therapy Modalities/))) and ((uptake or up-take or (up adj3 take*) or non-attend* or nonattend* or attend* or engag* or (treat* adj3 refus*) or decline* or concordan* or complian* or barrier* or obstacle* or adher* or accept*).ti,ab. Or exp treatment refusal/ or exp patient compliance/ or exp patient acceptance of healthcare/)

31 or 2

4 ((() Meta-Analysis as Topic/ or Meta-Analysis/ or exp Review Literature as Topic/) or ((meta analy\$) or (metaanaly\$) or ((systematic adj (review\$1 or overview\$1)))).tw. or (Cochrane or embase or psychlit or psyclit or psychinfo or psycinfo or cinahl or cinhal or (science citation index) or bids or cancerlit or reference list\$ or bibliograph\$ or hand-search\$ or (relevant journals) or (manual search\$)).ab. or ((selection criteria or data extraction).ab. and review/)) NOT (Comment/ or Letter/ or Editorial/)) Or (((Randomized Controlled Trials as Topic/ or randomized controlled trial/ or Random Allocation/ or Double Blind Method/ or Single Blind Method/ or clinical trial/ or exp Clinical Trials as topic/ or PLACEBOS/) or ((clinical trial, phase i) or (clinical trial, phase ii) or (clinical trial, phase iii) or (clinical trial, phase iv) or (controlled clinical trial) or (randomized controlled trial) or (multicenter study) or (clinical trial)).pt or ((clinical adj trial\$) or ((singl\$ or doubl\$ or treb\$ or tripl\$) adj (blind $\$ 3$ or mask $\$ 3)$ ) or (placebo\$) or (randomly allocated) or (allocated adj2 random\$)).tw) NOT (case report.tw or letter/ or historical article/))) or (quantitative or (mix* adj method*)).mp.

$5 \quad 3$ and 4
International Journal of COPD

\section{Publish your work in this journal}

The International Journal of COPD is an international, peer-reviewed journal of therapeutics and pharmacology focusing on concise rapid reporting of clinical studies and reviews in COPD. Special focus is given to the pathophysiological processes underlying the disease, intervention programs, patient focused education, and self management protocols.

\section{Dovepress}

This journal is indexed on PubMed Central, MedLine and CAS. The manuscript management system is completely online and includes a very quick and fair peer-review system, which is all easy to use. Visit http://www.dovepress.com/testimonials.php to read real quotes from published authors. 